\title{
$\bullet$ Correlates of Happiness Among Older Adults: A Systematic Review
}

\section{IJCRR}

Section: Healthcare

ISI Impact Factor

(2019-20): 1.628

IC Value (2019): 90.81

$\operatorname{SJIF}(2020)=7.893$

(c) (7) (8)

Copyright@IJCRR

\section{Chaudhary Richa ${ }^{1}$, Pandey Neelam², Dubey Anubhuti ${ }^{3}$}

'Ph.D Scholar, Amity Institute of Psychology and Allied Sciences, Amity University, Noida (UP), India; ${ }^{2}$ Assistant Professor, Amity lnstitute

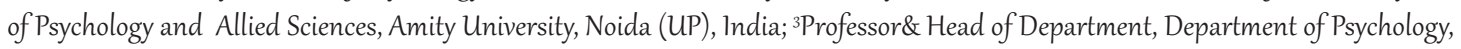
Deen Dayal Upadhyay Gorakhpur University, Gorakhpur (UP), India.

\section{ABSTRACT}

Introduction: The Aging Population is increasing rapidly and it is becoming an issue of global concern. It is increasing not only at the personal, experiential level but also at the global level because of the demographic and socio-cultural trends.

Aim and Objective: Papers meeting eligibility criteria and have similar aspects were selected through a sequential process of screening the title, abstract and full text. There was a dearth and requirement of Indian and other Asian studies. Different factors about happiness were seen as responsible for older adults. Acquiring good health, socioeconomic status, social support, physical fitness, cognitive health, culture, quality of life, self-esteem, life satisfaction \& various positive interventions are concluded as the different factors of happiness among older adults. Many other factors are also responsible for the happiness of older adults as well. Happiness is considered a key mark for every individual.

Conclusion: The Happier individual tends to live longer lives, enjoy better physical health, and possess greater psychological resilience. It is necessary to analyze and identify the major correlates of happiness focusing better and the positive aspects of older adults.

Key Words: Happiness, Older Adults, Factors of Happiness, Systematic Review, Ageing Population, Health

\section{INTRODUCTION}

As we all know old aged people play a crucial role in the world's population. The ageing population is increasing not only at the personal, experiential level but also at the global level because of the demographic and socio-cultural trends. India is one of the developing countries facing remarkable change. Sustained physical and cognitive decline, as well as social losses in old age, leads them to physiological and psychological effects.

Therefore, it is necessary to focus on the positive aspects of growing old and make ageing a happy period in life. The happiness of an individual plays a crucial role in one's life. It can be in different forms affecting an older adult positively. Maintaining a high level of happiness is considered to be the major aspect of positive ageing. Happiness not only revives an older adult but also gives the strength to deal with situations and hope for a better living. Understanding the true meaning of life is very important and happiness provides a booster for an older adult to live a positive life. Older people with happiness are precious for social, familial, intellectual, and for the overall development of themselves and the community. ${ }^{1}$

A contradiction is apparent in this situation because higher life expectancy is not directly related to healthy living since many elderly people are living longer but without the quality of life, currently depending on drugs or being kept in specialized institutions. The latest world report on ageing and health highlighted the need for a new global framework to cover the wide diversity of the older populations and address the inequalities beneath it. From a global perspective, the described needs focus on the development of a new health care system in the long term; a change in the way of understanding Ageing; encouraging the development of new approaches; and strengthening the capacity to assist older people in adapting to the changing environment (WHO, 2015). ${ }^{1,2}$

Happiness is an affective and emotional state which is characterized by the feeling of enjoyment and satisfaction. When we talk about ageing, it is often equated or linked

\section{Corresponding Author:}

Chaudhary Richa, Amity Institute of Psychology and Allied Sciences, Amity University, Noida, Uttar Pradesh, India. Phone: 09670392024; Email: richa.extreme0@gmail.com

ISSN: 2231-2196 (Print)

Received: 03.03 .2021
ISSN: 0975-5241 (Online)

Revised: 02.04 .2021
Accepted: 15.04 .2021
Published: 19.05 .2021 
with morale, contentment, well-being, life satisfaction, successful ageing, quality of life, and the good life. Happiness can be defined as a cognitive assessment of one's life. Positive psychology researcher Sonja Lyubomirsky focused on happiness as being the experience of joy, contentment, or positive well-being, in combination with a sense that one's life is good, meaningful, and worthwhile. ${ }^{2}$ Happiness is also based on the external criteria of virtue and holiness. Aristotle named such external measures as pride, friendliness, honesty, wittiness, intellectual virtue, rationality in judgment as well as scientific knowledge. Happiness can be stated as the experience of joy, contentment with a sense of meaningfulness. Among older adults, inner happiness is extremely necessary for the cultivation of meaningful living. Old age often brings energy loss, disease, meaninglessness, and many external problems so it becomes an important dimension to maintain the physical health and inner happiness of older adults. ${ }^{3,4}$

\section{METHODOLOGY}

The literature review was undertaken of the original research studies and articles on finding the correlates of happiness among older adults in India and other Asian countries. The studies and articles were searched on Research Gate and Google Scholar. The strategies for the search were used effectively and sequentially to obtain the studies available in the database. Factors of happiness among old age term was used frequently as an effective search strategy. The extensive search process decisively narrowed down to selecting around fifteen studies. The inclusion criteria for the selection of the studies focused on the correlates of happiness, and how other factors are responsible for the happiness of older adults. Studies which were not fulfilling the inclusive criteria were excluded. Research and studies extracted were full-text papers focusing on Asian countries and the reference period of the study was the past 10 years. The quality of the research studies was assessed based upon the research design, inclusion-exclusion criteria, sample size, systematic definitions, and sampling strategies.

\section{REVIEW OF LITERATURE}

Srinivasan Chokkanathan \& Jayashree Mohanty did the research is done on the Factor Structure of the Centre for Epidemiological Studies- Depression Scale among older adults in Chennai, India by This study investigates the psychometric properties of the 20 -item and collections of data was from the 200 community-dwelling older adults aged 65 years and above, residing in Chennai, India. The data was separated for exploratory factor analysis and confirmatory factor analysis randomly. On a subsample $(\mathrm{n}=200)$ Exploratory factor analysis yielded two factors, depressed, and positive. The internal consistency was found higher for the total scale and its subscales. The results indicated acceptable measurement properties of the Centre for Epidemiological Studies Depression Scale. There is a dearth of investigation and studies among Indian older adults. ${ }^{3}$

Brasher \& George et al. did the research conducted on Incorporating biomarkers into the study of socio-economic status and health among older adults in the chin. The social gradient in health that the individual with lower socio-economic status has worse health than those of the higher socio-economic status is done using self-reports of health in more developed countries. The sample was collected from the Chinese Longitudinal Healthy Longevity Survey to find the social gradient in health among rural young old and oldest-old adults $(\mathrm{N}=2$, 121). Individual biomarkers, metabolic syndrome, and selfreports of health are important health indicators. There was a positive relationship between socioeconomic status and health. Socioeconomic status was more associated with individual biomarkers among the oldest old than the young old, providing pieces of evidence for cumulative disadvantage. ${ }^{4}$

Mamta Chaudhary researched the topic Socio-Economic Gradients in Frailty among older adults in India: An Exploration using Strategic Advisory Group of Experts data. This study helps to fill the gap using older adults aged 50 or over from the study on global ageing and adult health. The objective was to examine the association of frailty with socioeconomic status and how its association differs across different age groups. Results show that socioeconomic status was negatively associated with the prevalence of the number of frail markers with a decrease overage group while adjusting and un-adjusting for background characteristics and healthrisk factors and biomarkers. Around $26 \%, 55 \%$, and $20 \%$ of participants presented no frailty marker, 1-2 trail markers, and 3-4 frailty marker respectively. The total number of frailty markers was positively associated with lower income and education level in the case of controlling and not controlling groups. There was a higher chance of being frail in the case of higher age group individuals with low socioeconomic status. Thus, the higher prevalence of frail markers in the low socioeconomic status older age group focuses on the need for comprehensive and centred public health interventions for the older adults with low socioeconomic status. ${ }^{5}$

Research named Happiness and Cognitive Impairment among Older Adults: To investigate the roles of Depression, Disability and Loneliness by Tan \& Abdin. This study shows the understanding of the lower level of happiness among older adults with cognitive impairment has been an issue of neglect. The finding shows the happiness level among older adults in Singapore and finds the potential mediating roles of depression, disability, social contact frequency, and loneliness in distinguishing happiness and cognitive scores. 
Around $96.2 \%$ of the sample reported feeling either slightly happy or very happy. In the regression analysis, individuals of Malay descent, those who were married/cohabiting or had higher education levels were more at odds of reported happiness. After controlling socio-demographic factors, higher cognitive scores were seen associated with higher disability, depression, loneliness, and the frequency of contact with friends. The majority of the older adult population reported fairly happy or very happy while the cognitive impaired showed limited reversibility in past studies. Unhappiness among older adults with cognitive impairment might be potentially mitigated through interventions addressing the accompanying issues of social isolation, disability, and depression. ${ }^{6}$

Shu Hu \& Dhiman Das conducted the research "Quality of life among older adults in China and India: Does productive engagement help"? Individuals in developing countries are often engaged in paid or unpaid works till late in life due to low household savings and limited welfare provisions. While work can be beneficial for economic and psychological well-being, this paper focuses on whether engagement in paid and unpaid work mediates the impact of physical disabilities on the quality of life for older adults. Exploration of different levels of health service and social security in rural and urban China and India was done to examine the effect of public provisions in the process. Through the casual mediating analysis framework, it was found that paid work plays a minor role in mediating the effect is smaller in urban China than in other societies. The findings of this paper indicate that promoting productive engagement alone, without improving basic public provisions will have a limited impact on improving the quality of life of the ageing population in developing countries. ${ }^{7}$

Nazri \& Vanoh conducted a study entitled Malnutrition, Low Diet Quality, and its Risk Factors among Older Adults with Low Socioeconomic Status: A Scoping Review. This paper focuses on the available literature to find the prevalence of malnutrition, poor diet quality, and its associated risk factors among older adults with lower socioeconomic status. Most of the studies (60\%) included in this review used Body Mass Index as the tool to identify malnutrition, but none of the nutritional screening tools was considered to be the gold standard. Older adults with low socioeconomic status show a poor nutritional status and lack of good quality diet. Hence, it is important to establish nutrition-related programs and interventional studies among older adults to improve their health status as well as their quality of life. ${ }^{8}$

Table 1 below describes the various reviewed studies taken into concern along with their descriptions. Table 2 states the different correlates of Happiness. There is also a pie chart in Figure 1 to describe the importance of each correlates respectively.

\section{RESULTS}

\section{Table 1: Description of the reviewed studies}

\begin{tabular}{|c|c|c|c|c|c|c|}
\hline Title & Author & $\begin{array}{l}\text { Name of the } \\
\text { Journal }\end{array}$ & Study Design & Location & $\begin{array}{l}\text { The tool used } \\
\text { for the injury } \\
\text { survey }\end{array}$ & Study Size \\
\hline $\begin{array}{l}\text { Effect of physical } \\
\text { exercise Program on the } \\
\text { happiness among older } \\
\text { adults }\end{array}$ & $\begin{array}{l}\text { M. khazae- } \\
\text { pool et al ., } \\
2015\end{array}$ & $\begin{array}{l}\text { Journal of } \\
\text { Psychiatric and } \\
\text { Mental Health } \\
\text { Nursing 22(1) }\end{array}$ & $\begin{array}{l}\text { Randomized } \\
\text { control trial }\end{array}$ & $\begin{array}{l}\text { Nowshahr, } \\
\text { Iran }\end{array}$ & $\begin{array}{l}\text { Physical Exercise } \\
\text { Program (PEP) }\end{array}$ & $\begin{array}{l}120 \text { older } \\
\text { adults }\end{array}$ \\
\hline $\begin{array}{l}\text { Role of social, cultural } \\
\text { and economic capitals } \\
\text { in perceived quality of } \\
\text { life among old age peo- } \\
\text { ple in Kerala, India }\end{array}$ & $\begin{array}{l}\text { Pradeep } \\
\text { Deshmukh et } \\
\text { al., } 2015\end{array}$ & $\begin{array}{l}\text { Indian journal of } \\
\text { Palliative Care }\end{array}$ & $\begin{array}{l}\text { Community } \\
\text { based cross sec- } \\
\text { tional study }\end{array}$ & $\begin{array}{l}28 \text { villages of } \\
\text { Kollam dis- } \\
\text { trict, Kerala, } \\
\text { India }\end{array}$ & $\begin{array}{l}\text { WHO-Quality } \\
\text { of Life - BREF } \\
\text { questionnaire }\end{array}$ & $\begin{array}{l}900 \text { old aged } \\
\text { people }\end{array}$ \\
\hline $\begin{array}{l}\text { Factors associated } \\
\text { with the life satisfac- } \\
\text { tion amongst the rural } \\
\text { elderly Odisha, India }\end{array}$ & $\begin{array}{l}\text { Pallavi Ban- } \\
\text { jare ., } 2015\end{array}$ & $\begin{array}{l}\text { Health and } \\
\text { quality of life } \\
\text { outcomes }\end{array}$ & $\begin{array}{l}\text { Cross sectional } \\
\text { survey using } \\
\text { multi stage ran- } \\
\text { dom sampling }\end{array}$ & $\begin{array}{l}\text { Bargarh dis- } \\
\text { trict, Odisha, } \\
\text { India }\end{array}$ & $\begin{array}{l}\text { Hierarchical } \\
\text { regression analy- } \\
\text { sis }\end{array}$ & $\begin{array}{l}310 \text { old aged } \\
\text { people }\end{array}$ \\
\hline $\begin{array}{l}\text { Health and Happiness } \\
\text { among community- } \\
\text { dwelling older adults } \\
\text { in Domkhar Valley, } \\
\text { Ladakh, India }\end{array}$ & $\begin{array}{l}\text { Ryota Saka- } \\
\text { moto ., } 2016\end{array}$ & $\begin{array}{l}\text { National Library } \\
\text { of Medicine }\end{array}$ & Analysis of data & $\begin{array}{l}\text { Domkhar val- } \\
\text { ley, Ladakh, } \\
\text { India }\end{array}$ & $\begin{array}{l}\text { Geriatric Depres- } \\
\text { sion Scale and } \\
\text { the Visual Analog } \\
\text { Scale for subjec- } \\
\text { tive quality of life }\end{array}$ & $\begin{array}{l}117 \text { older } \\
\text { adults }\end{array}$ \\
\hline
\end{tabular}


Table 1: (Continued)

\begin{tabular}{|c|c|c|c|c|c|c|}
\hline Title & Author & $\begin{array}{l}\text { Name of the } \\
\text { Journal }\end{array}$ & Study Design & Location & $\begin{array}{l}\text { The tool used } \\
\text { for the injury } \\
\text { survey }\end{array}$ & Study Size \\
\hline $\begin{array}{l}\text { Age and socioeconomic } \\
\text { gradients in frailty } \\
\text { among older adults in } \\
\text { India }\end{array}$ & $\begin{array}{l}\text { Mamta } \\
\text { Chaudhary ., } \\
2019\end{array}$ & $\begin{array}{l}\text { Springer Verlag } \\
\text { GmbH Germany }\end{array}$ & $\begin{array}{l}\text { Modified fried } \\
\text { phenotype ap- } \\
\text { proach with five } \\
\text { frailty indicators }\end{array}$ & India & $\begin{array}{l}\text { Multinomial lo- } \\
\text { gistic regression }\end{array}$ & $\begin{array}{l}6560 \text { older } \\
\text { adults }\end{array}$ \\
\hline $\begin{array}{l}\text { Hypertension and } \\
\text { cognitive health among } \\
\text { older adults in India }\end{array}$ & $\begin{array}{l}\text { Madeline R. } \\
\text { Farron ., et al } \\
2020\end{array}$ & $\begin{array}{l}\text { Journal of Amer- } \\
\text { ican Geriatric } \\
\text { Psychology }\end{array}$ & $\begin{array}{l}\text { Longitudinal Ag- } \\
\text { ing study }\end{array}$ & $\begin{array}{l}\text { Geriatric } \\
\text { hospital and } \\
\text { respondent } \\
\text { home across } 14 \\
\text { states in India }\end{array}$ & $\begin{array}{l}\text { Longitudinal } \\
\text { Aging Study in } \\
\text { India-Diagnostic } \\
\text { Assessment of } \\
\text { Dementia (LASI- } \\
\text { DAD) }\end{array}$ & $\begin{array}{l}\text { 2,874 older } \\
\text { adults }\end{array}$ \\
\hline
\end{tabular}

Table 2: Various Correlates of Happiness found are as follows

\begin{tabular}{ll} 
S. No. & Correlates of Happiness \\
1. & Physical Exercise \\
2. & Quality of Life \\
3. & Life Satisfaction \\
4. & Health \\
5. & Self Esteem \\
6. & Socio Economic Status \\
7. & Cognitive Health \\
8. & Positive Intervention \\
\hline
\end{tabular}

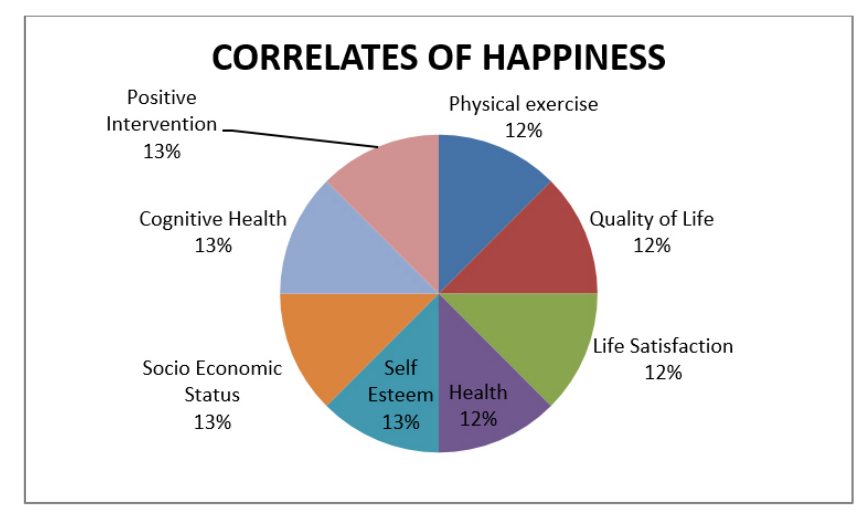

Figure 1

\section{DISCUSSION}

\section{The various Correlates of Happiness are:}

\section{Physical Exercise}

In the ageing population, physical fitness and exercise help in preventing disease, lower the risk of falls, improve mental health and well-being, strengthen social ties, and improves cognitive function. Khazaepool \& Sadeghi did the study was done entitled Effect of physical exercise Program on the happiness among older adults, Journal of
Psychiatric and Mental Health Nursing 22. In the above study, the randomized control trial investigated the effect of physical exercise programs on happiness among older adults of Nowshahr, Iran. On the sample of 120 male and female volunteers, the results showed that an 8-week group physical exercise program was significantly effective in older adult's happiness. It is clear from the above study that Physical activity is associated with well-being and happiness. The data was collected in Nowshahr, Iran for 120 males and females. Participants were asked to complete the tool before and 2 months after implementing the Physical Exercise Program. The 8-week Physical Exercise Program was done with the intervention group. There was no significant difference in the happiness mean score between the case and control groups before the intervention; however, the experimental group was significantly improved by happiness after implementing the Physical Exercise Program $(p=0.001)$ and was not improve within the control group $(\mathrm{p}=0.79) .{ }^{9}$ Planning and implementing physical activity in day-to-day life is important for happiness among older adults.

\section{Quality of Life}

Good quality of life is important for older adults mainly the ones dealing with major life changes and other chronic illnesses. One must feel useful or needed and keeping them- 
selves mentally active is a creative task to make them a happy person in and out. Deshmukh \& Dongre et al. researched with the title Role of social, cultural, and economic capitals in perceived quality of life among old age people in Kerala, India, Indian Journal of Palliative Care. This study was done to find the relationship between collective social, economic, and cultural properties of a population on the perceived quality of life among old age people. The psychological health domain and environment domain was seen troubled by all three capitals significantly. But, the social relation domain was significantly affected only by cultural capitals. Hence, the strategies for old people should envision keeping our cultural and social norms along with the economic interventions for better palliative care.

\section{Life Satisfaction}

Life satisfaction is considered as the key factor for the successful ageing of older adults. When it comes to the happiness of older adults, life satisfaction plays a prominent role. It helps to support physical and cognitive decline as well as social losses in old age. Banjare \& Dwivedi et al. did the research entitled Factors associated with the life satisfaction amongst the rural elderly Odisha, India. Life satisfaction is the measure of subjective well-being and is directly associated with health and mortality among older adults. There were altogether 310 respondents. In the results, cognitive health was the most influential factor in determining life satisfaction among both men and women. There was significantly lower perceived Life Satisfaction for both genders who are living alone and have a disability and had a low score of activities of daily living. ${ }^{10}$ It is important to analyze and focus on the major factors which can enhance the level of Life Satisfaction among the elderly population. A better understanding of these factors helps in removing the anxiety of old age in the mindset of people which is pervading society.

\section{Health}

Keeping ourselves healthy helps to relieve chronic pain from conditions like arthritis and pinched nerves. Concerning old age, being healthy help in preventing us from developing diseases such as obesity and diabetes, improves our metabolism, lowers blood pressure, and strengthens our immune system. The study titled Health and Happiness among community-dwelling older adults in Domkhar Valley, Ladakh, India by Sakamoto \& Okumiya. The survey of 117 people aged 60 years or old in Domkhar, and age- and sex-specific Japanese were taken into consideration. It was found that the subjective quality of life of the people of Domkhar was higher in comparison to Japanese controls despite a higher rate of difficulty in the basic activities of daily living. We should not only consider prevention, treatment, and care for the disease and disability but also the loneliness of older adults. ${ }^{10}$

\section{Self Esteem}

Removing the negative stereotypes and maintaining balance in life helps to develop self-esteem among older adults. Interaction with the people and talking about the current events helps to develop a meaningful interaction among the old aged people. The study entitled Predictors of happiness among older Korean women living alone: Predictors of happiness by Kim \& Song et al. (2019). The level of happiness of older adults is associated with their psychosocial as well as physical health. This study focuses on identifying the predictors of happiness. Health-related information, perceived selfesteem, and Depressive symptoms as independent variables predicting happiness were the demographic factors seen. Descriptive statistics and multivariate analysis were taken into concern. While checking the result, 154 participants were recruited. They showed a moderate level of happiness. Even, happiness was negatively related to comorbidities, presence of pain, depressive symptoms but positively correlated with self-esteem. ${ }^{11}$ The happiness of the older women was linked with self-esteem and depressive symptoms.

\section{Socio Economic Status}

Socioeconomic status provides a good quality of life and other life attributes that help to lead a happy life among older adults. Socio-economic status has been found to affect the psychological health of the ageing population. Mamta Chaudhary \& Ravindra Chowdhary (2019) did the study named Age and socioeconomic gradients in frailty among older adults in India. Older adults with frailty and lower socioeconomic status are endangered to morbidity and early mortality. The main objective of the above research was to find the relation of frailty with socioeconomic status and how this relationship varies across different age groups. Frailty measure was positively associated with the lowerincome and education level in the event of controlling and not controlling for confounders. Also, among the higher age groups, there was a higher chance of being frail who belong to low socioeconomic status. ${ }^{12}$ The overall result of the study showed that socio-economic status majors a major role for older adults to be frail.

\section{Cognitive Health}

Cognitive health is responsible for focusing and remembering the positive events and leaving behind the negative ones. The processes and what they think helps to regulate their emotions letting them positively view their life. Farron \& Kabeto et al. (2020) conducted research entitled Hypertension and cognitive health among older adults in India. This research evaluates the prevalence of diagnosed and undiagnosed hypertension and its association with cognitive function in older adults in India. Factors associated with poor cognitive test performance were Older age, female sex, less education, being widowed consumption is seen low and are underweight. Around two-thirds 
of the older Indian individual had hypertension with the majorly being undetected or detected but not adequately controlled. ${ }^{13}$ Hypertension was not self-sufficient with cognitive function, whereas socio-demographic factors were sufficient for cognitive function.

\section{Positive Intervention}

Having a positive view of life is an important aspect of being happy. Positive intervention helps to build up a series of actions or positive behavioural strategies to increase the wellbeing and optimism among older adults. Ramirez \& Ortega et al. conducted a Program of positive intervention in the elderly. The main goal of the study was to increase the quality of life in people over 60 years through a positive psychology intervention. The variables to be measured were subjective happiness, State and trait anxiety, depression, general memory, specific memory, life satisfaction. The results revealed that participants who followed the program (experimental group) showed a significant decrease in state anxiety, depression as well as an increase in specific memories, life satisfaction, and subjective happiness compared with the placebo group. The positive intervention provides positive effects on the elderly, helping them increase subjective well-being and quality of life. ${ }^{14}$ Such types of positive interventions help in the enhancement of personal and social resources for being happy.

\section{CONCLUSION}

Among old age, where the losses are frequent it becomes foremost important to continue the growth-related goals for promoting well-being, rather than focusing totally on losses. The above finding shows the multiple factors responsible for the happiness of older adults. The different factors are wellbeing, quality of life, life satisfaction, self-esteem, financial well-being, work status, health, forgiveness, social relationship, and positive thinking. It is true that every person has different priorities and mindsets. We can't find all the factors in all individuals. There can be an increase and decrease of the factor depending on the mindset of the person. They need to imbibe these factors to live a quality life, healthy and happy.

We already know that this population is very challenging. Older adults generally have energy loss, disease, meaninglessness, and many external problems. This is the age of having internal as well as external happiness. Old age people generally focus on wisdom and experience. More developed intelligence, happiness results in a balanced inner life. Therefore, It is been scientifically proven through the different reviews done above. These are the factors responsible for the happiness of Older Adults. Happiness is considered a key mark for every individual. The happier individual tends to live longer lives, enjoy better physical health, and possess greater psychological resilience.

Old age is not only about how old are you but how much good time you had and how positively you are carrying your life. We become much wiser and people's opinions do not easily fluster us. We become comfortable with our skin. Having a sense of purpose and staying connected plays a different positive role in one's life. Hence ageing happily is in the individual's hands. Social relationships, self-esteem, well-being, quality of life, life satisfaction, health, work status, positive thinking, economical needs, forgiveness are the important supplements of happiness that help older adults to live a positive life. It just takes giving some respect and care to the elderly to make them happy people.

\section{ACKNOWLEDGEMENT}

The authors acknowledge the immense help received from the scholars whose articles are cited and included in references to this manuscript. The authors are also grateful to authors/editors/publishers of all those articles, journals and books from where the literature of this article has been reviewed and discussed.

\section{Conflict of Interest: None}

\section{Sources of funding: None}

\section{Individual Author's Contribution}

The first author contributed the manuscript by going through various research papers, articles and journals relevant to Happiness among Older Adults and another inclusive criterion. Processing, Writing, Analysing, Interpreting the Result, Discussion and Conclusion are covered by the first author. The second author planned, analysed and supervised the manuscript. Both the authors discussed the result and conclusion. The third author critically analyzed and reviewed the manuscript.

\section{REFERENCES}

1. World Health Organization. World report on ageing and health (W.H.Organization, Ed.): World Health Organization. Luxembourg: World Health Organization. 2015.

2. Lyubomirsky S. The how of happiness: A scientific approach to getting the life you want. New York: The Penguin Press. 2008.

3. Chokkanathan S, Mohanty J. Factor structure of the CES-D scale among older adults in Chennai, India. Aging \& Mental Health. 2013; 17(4): 517-525.

4. Brasher M, George L, Shi X, Yin Z, Zeng Y. Incorporating biomarkers into the study of socio-economic status and health among older adults in China. SSM - Population Health; 2017.

5. Chaudhary M. Socio-economic gradients in frailty among older adults in India: An Exploration using SAGE data. J Public Health. 
6. Tan JH. Happiness and Cognitive Impairment among Older Adults: Investigating the Mediational roles of Disability, Depression, Social Contact Frequency and Loneliness. Int J Environ Res Public Health. 2019; 16(24):310.

7. $\mathrm{Hu} \mathrm{S}$, Das D. Quality of life among older adults in China and India: Does Productive engagement help. Soc Sci Med. 2019;23(4):59-62.

8. Nazri NS, Vanoh D, Leng SK. Malnutrition, Low Diet Quality and its risk factor among Older Adults with low Socio-Economic Status: A Scoping Review. Nutr Res Rev. 2020;23(6):72

9. Khazaepool M, Sadeghi R, Majlessi F, Foroushani AR. Effect of Physical Exercise Program on the Happiness among Older Adults. J Psychiatr Ment Health Nurs. 2015; 22(1):47-57.

10. Banjare P, Dwivedi R, Pradhan J. Factors associated with the life satisfaction amongst the rural elderly in Odisha, India. Health And Quality Of Life Outcomes. 2015; 13(1):91-93.
11. Kim J, Song Y, Kim T, Park K. Predictors of happiness among older Korean women living alone. Geriatr Gerontol Int. 2019;32(5):213.

12. Chaudhary M, Chowdhary R. Age and socioeconomic gradients in frailty among older adults in India. J Public Health. 2018; 27(5): 675-685.

13. Farron MR, Kabeto M, Dey AB, Banerjee J, Levine DA, Langa $\mathrm{K}$. Hypertension and Cognitive Health among adults in India. J Am Geriatr Soc. 2020;9(2):45-49.

14. Ramírez E, Ortega A, Chamorro A, Colmenero J. A program of positive intervention in the elderly: memories, gratitude and forgiveness. Age Men Heal. 2013; 18(4):463-470. 